\section{ROYAL COLLEGE OF SURGEONS OF ENGLAND.}

AN ordinary meeting of the Council was held on June 9th, Mr. JoHN TwEedy, the President, being in the chair.

It was resolved that diplomas of Fellowship should be issued to 16 candidates, two being postponed because the candidates were under age.

It was resolved that diplomas of the Licence in Dental Surgery should be issued to 46 successful candidates.

In accordance with the recommendation of the Museum Committee it was resolved that rooms Nos. 1 and 4 of the museum should be painted and that the museum should be closed during Angust and September to permit of the painting being done.

A report was read from the committee on the Relations of the Medical Profession to the Ooroner's Court. It was approved and entered on the minutes. The committee had inquired into the matter and had examined the recommendations put forward by the British Medical Association and by the London County Council and had found ample proofs of the desirability of alterations in the present laws, but the questions involved are varied and include matters of administration, such as the rearrangement of coroners' districts, with which the medical profession is not immediately concerned. Having regard to the various interests concerned and to the failure of other institutions to induce the Government to initiate legislation, the committee was of opinion that it would not be expedient for the Oollege to take any action in the matter at the present time.

The PRESIDENT laid before the Council a letter which he had received from the Home Secretary and reported that be proposed to recommend Dr. William Henry Willcox of St. Mary's Hospital as official analyst to the Home Office in the vacancy occasioned by the resignation of Dr. A. P. Luff. The Council approved of the recommendation.

A letter was read from Mr. Henry Morris reporting the proceedings of the General Medical Council at its recent session. The thanks of the Council were given to $\mathrm{Mr}$. Morris for this letter.

It was resolved that the revised regulations for study in chemistry and physics shall apply to those who register as dental students as well as to those registering as medical students on or after June 1st, 1904, and that the new synopsis of the examinations shall take effect in and after March, 1905.

A petition was read, signed by 264 candidates for the diploma in dental surgery, asking the Oouncil to take into consideration the following suggestions :-1. The publication of a reasonably detailed syllabus giving the general range of knowledge required in $(a)$ surgery, $(b)$ anatomy, and $(c)$ physiology, as has been done in the subjects of chemistry and metallurgy. 2. The institution of a quarterly examination as for the M.R C.S. diploma. Half-yearly examinations enforce an unnecessarily long interval after failure, entail extra expense, and tend to engender a dilatory spirit in the candidates. The petition was referred to the Board of Examiners in Dental Surgery to consider and to report.

A report was read from the committee on Diplomas in Tropical Medicine in favour of instituting an examination and a diploma, and it was decided to invite the Roya College of Physicians of London to appoint representatives to confer with representatives of the College on this subject.

A letter was read from a Fellow of the College submitting a statement in regard to a case of sudden death to which he was called and the action of the coroner for the south.western district of the county of London in reference thereto, and asking the Council to take such steps as shall appear proper to it to defend the College from the inferential aspersion cast upon it by this coroner that a Fellow of the College is not competent to give evidence in his court or to perform a necropsy.

The following examiners were appointed :-

Board of Examiners in Anatomy and Physiology for the Fellowship.-Anatomy : Louis Albert Dunn, Arthur Keith, Christopher Addison, and William McAdam Eccles. Physiology : Edward Waymouth Reid, Ernest Henry Starling, Leonard Erskine Hill, and De Burgh Birch.

Conjoint Examining Board.-First Examination-Elementary Biology : Herbert Willoughby Lyle, Walter G. Ridewood, Thomas George Stevens, and Henry William Marett Tims.
Second Examination-Anatomy: Holburt Jacob Waring, Arthur Keith, Christopher Addison, and James Ernest Lane. Physiology: William Henry Thompson, Thomas Grigor Brodie, and John Beresford Leathes. Third IxaminationMidwifery : William Duncan, James Henry Targett, George Francis Blacker, and Arthur Hamilton Nicholson Lewers.

Examination in Public Health. - Part I. : Alexander G. R. Foulerton. Part II. : Herbert Timbrell Bulstrode.

In response to a letter from Sir $\mathrm{R}$ Douglas Powell, Bart., the Council granted permission to the Royal Medical and Chirurgical Society to hold a conversazione at the College in May, 1905, in connexion with the celebration of the centenary of the society.

A vote of thanks was given to Mr. Thomas Bryant for his long and zealous services to the College as a member of the Council.

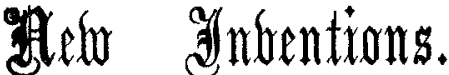

\section{A NEW CHLORIDE OF ETHYL INHALER.}

THE accompanying illustration represents an inhaler for chloride of ethyl of my own design which I have used with marked success for the past 12 months. The following are some of the advantages which may be claimed for it: (1) direct and immediate contact with the chloride of ethyl vapour as there is no medium such as lint which is apt to get frozen and become inert; (2) a continuous discharge of a jet of chloride of ethyl during the short time necessary to produce anæsthesia; (3) the presence of an insoluble residual chamber into which the chloride of ethyl drops and volatilises; (4) the absence of necessity for measurement and special bottles ; and (5) facility of manipulation, as the ordinary tube can be opened and slipped on in a second or two. A very short time is required for the induction of

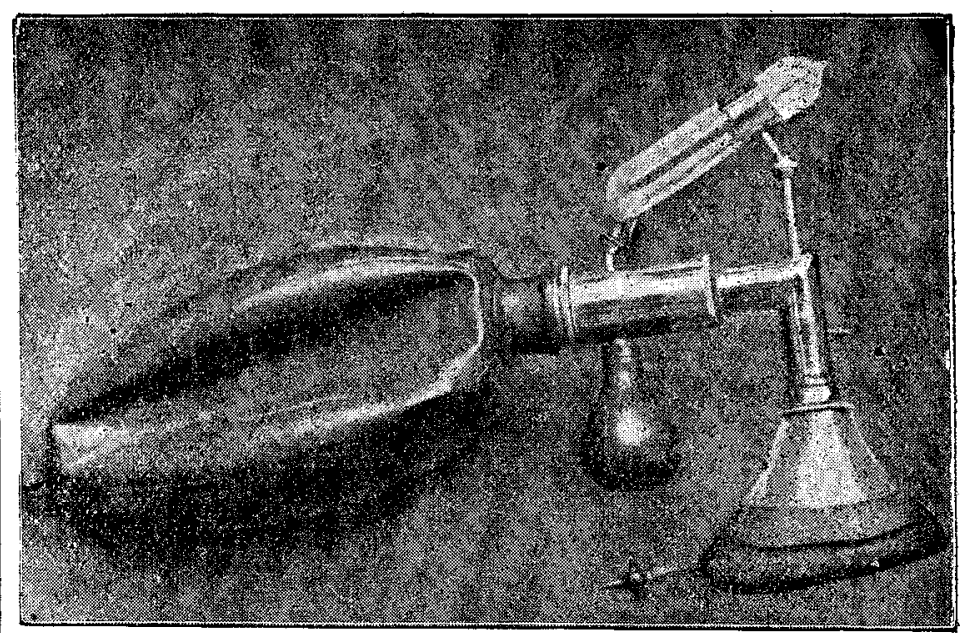

anæsthesia; the average time is 30 seconds and it may be as short as 15 seconds. The average period of available anæsthesia is one and a quarter minutes.

In administration the inhaler is placed firmly and closely over the patient's nose and mouth. (In dental cases a mouth prop or gag is placed in position before commencing.) The air valve is opened and two deep inspirations are allowed to fill the respiratory bag. The air valve is then closed and unconsciousness with full stertorous breathing will rapidly ensue. The inhaler is made by the Dental Manufacturing Company, 6 to 10, Lexington-street, London, W. J. MaXwell Wood, M.B., C.M., L.D.S. Edin.

Dumfries.

Drlapidated Russian Hospital Buildings.The Russki Viedomosti relates that in Juriev the public hospitals, pharmacies, and other analogous institutions are in a most dilapidated condition and in one of the hospitals the other day a large portion of the ceiling fell, simply through age, and killed a patient, wounding a nurse at the same time. It is stated that the fears for the safety of the other houses are based on bad material used in the buildings as well as on their age. 